\title{
British Army Recruits: 100 Years of Heights and Weights
}

\author{
Dr S Rosenbaum \\ MA, PhD \\ Formerly Principal Scientific Officer AMD Stats
}

\author{
Maj Gen (Retd) J P Crowdy \\ $\mathrm{CB}, \mathrm{FFPHM}$ \\ Formerly Commandant \& Postgraduate Dean Royal Army Medical College
}

SUMMARY: The heights and weights of Army recruits have been placed on record since 1860 in Reports of the Arm\% Medical Department with certain gaps, particularly during the tw o World Wars and the period between them, until theig publication was discontinued in 1975. Mean values corrected where necessary for minimum standards of height and weight - in order that the results should represent the civilian population from which they were drawn - are presented showing the trends over a century. The $Q$ uetelet index w/ $/ h^{2}$, an indicator of weight corrected for height, is recommended. as a measure of obesity for the Army. The value to the Army Medical Services of a continuously published record of heights and weights is assessed, and the hope is expressed that publication of these data will be recommenced.

\section{Introduction}

A paper bearing the second half of the title above, published recently (1), constituted a review of height and weight data for Great Britain back to the 1880 s and before. A principal feature for establishing trends, especially among young adult males, was the long series for Army recruits appearing in Army Medical Department (AMD) Reports, albeit with breaks as during the inter-war years. This series is reported here in greater detail - previously the data were in 5-year groups - and comments are offered on the use of such data to military medicine.

In 1883 the Anthropometric Committee of the British Association for the Advancement of Science produced the final report on the heights, weights and other physical characteristics of the inhabitants of the British Isles that it had been appointed in 1875 to collect. Although there were gaps in the coverage, especially in respect of women, height and weight data were fairly extensive, relying necessarily on institutions such as schools and the Army. The numbers were about 37,000 males and 4,600 females (over 12,000 were schoolchildren, 6,000 military and police, 6,400 Post Office messengers etc, 3,500 criminals, and some others such as employees of Whiteley's). It is clear that, though the Committee had obtained the co-operation of a "large number of independent observers living in different parts of the country", the results were not able, as they stood, to represent the general population - something not achieved, at any rate among adults, until a survey was carried out by the Office of Population Censuses and Surveys (OPCS) on behalf of the Department of Health and Social Security (DHSS) in 1980 (2). A bias existed towards measurements taken among the professional classes - the public schools for example were able to provide the data more readily - so a method was adop- ted to compensate for this by averaging the means for the various classes. Unfortunately the method was inadee quate in not allowing for the differing numbers in thgse classes and omitted altogether the lowest class coinc prising $11 \%$ of the population. The resulting upwâक bias meant that, for a long time afterwards, Ahis. authoritative report provided too high a criterion $x_{0}$ judging the "degeneracy of the population", alread 8 cause for concern at the time the report was being itit ten. It led, in 1917-18, to alarm being felt about ancips parently stunted population, revealed by the Nationte Service Medical Board's measurements of men of milkू tary age then being called up.

A more subtle cause of bias in the Anthropometrif Committee's results was their dependence, to a large extent, on soldiers and recruits in their sample of adults? Recruits, at least, were drawn from the general populas tion, but there were, in particular, height limits that ensured an upward bias on the average of any group that: included them. For many years the minimum stood ate 64in, and for some arms was occasionally raised to 66in and once even to $68 \mathrm{in}$ for a short while. A method exis 8 for correcting this bias in so-called truncated data though there are difficulties in its practical application as will be explained, and the resulting estimates can be somewhat variable.

The Anthropometric Committee's Report had an appendix showing the heights and weights of Army res cruits as early as $1860-64$, but made no direct use of the figures. Indeed, such data, at least as far as heights were. concerned, were no longer published on a regular basiog until they appeared in AMD Reports from 1879 - too late for the Committee to make use of them. By the outbreak of the first World War over $1 \frac{1}{2}$ million meass urements had been reported, enabling a trend to 
established which, if not a precise replica of the whole population, is probably parallel to it. In the present paper, every available year has been analysed and, as could be anticipated, the results do not plot as smoothly as the 5-year groups analysed previously. It is worth rehearsing some of the reasons, apart from the statistical fact that group means are less variable than individual years. In theory, for data which are normally distributed (in the technical statistical sense) as heights are, approximately, wherever the truncation takes place calculations on the remainder should yield the same estimate of the mean and standard deviation of the full distribution. To take an example, it should be possible from a sample of Guardsmen to estimate the average height of all young males. However the reliability of the estimate diminishes as the truncation point increases; in particular, where the truncation occurs at a point near the mean value the result can be quite wide of the mark, as in the 19th century when the average height at the age of 18 was only about $64 \mathrm{in}$. A further technical difficulty attaches itself to the estimate of weights, which are far from being normally distributed; this is dealt with by a logarithmic transformation which compresses the upper tail of the distribution towards a symmetry with the lower. But more serious are the complications due to the elasticity of standards, as when a recruit hovered on the border of acceptability; and false declarations of age, due either to an eagerness to join or, as one comment put it, below $18 \mathrm{did}$ not count for pension. The sources of data on recruits have varied over time, from primary inspections by civilian medical practitioners, as well as by Army medical officers at Regimental Depots and at HQs of Recruiting Districts, to final approval for service which became the customary source in the 1880 s. Furthermore, there was a reorganisation of regiments following the Cardwell reforms of the 1870 s, with one battalion at home and one abroad.

The First World War disrupted the production of AMD Reports, and we have only the National Service Medical Board's report, already referred to, which related to the Birmingham area. The inter-war years saw the resumption of AMD Reports which were much slimmer volumes than previously and carried no table of heights and weights at all, other than the year 1937 when a new system was being introduced which enabled Southern Command to report its figures. The Second World War put a stop to this and we are able only to quote Martin (3) on the militia called up in 1939, Clements and Pickett (4) on a sample called up in 1941, and a small sample for 1942-44, results for which are given in the Statistical Report on the Health of the Army for 1943-45. Thereafter figures were again published from 1951 and continued until 1974, bringing the total number of military measurements to about 3 million. This later period has not required any correction to take account of minimum standards because the population mean has risen so as to render the effect nugatory.
Table 1

\section{Heights of recruits (inches) 1860-1974}

Age 18 20-24*

Age 18 20-24*

Age $18 \quad 20-24$

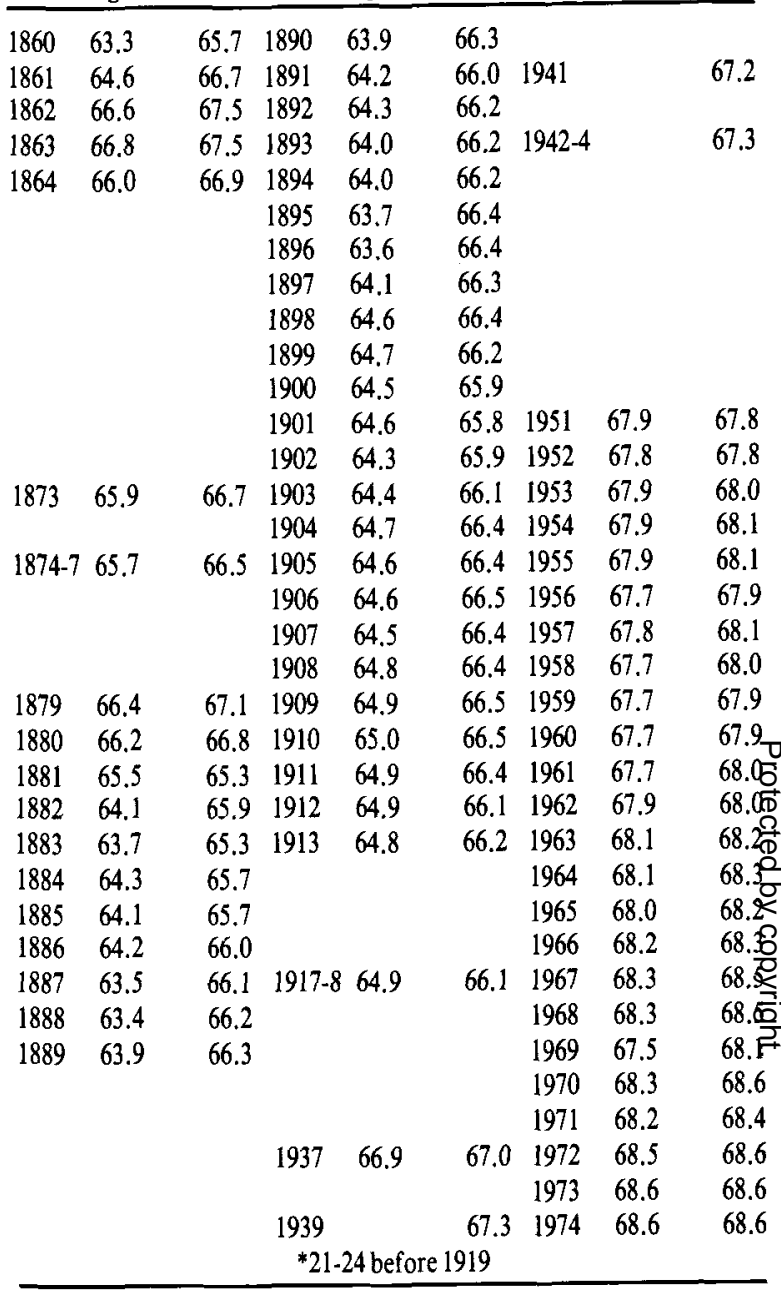

\section{Heights}

Average heights in each year, at age 18 last birthday and ages 20-24 (21-24 before 1919), are shown in Table 1 and are plotted in Fig 1. The reason for excluding age 20 in the earlier period is that young men of this age were still growing whereas in the later period growth had generally ceased. The amount of further growth after ages 21-24 was, on average, about $0.6 \mathrm{in}$.

Initially heights were stated to have been taken "barefoot", but in more recent times it has merely been prescribed that boots and shoes should be removed. Morant, who did a great deal of anthropometric work for the Institute of Aviation Medicine, ran an experiment (5) in which he measured the heights of 520 aircrew, both with and without socks, and found a difference of $0.27 \mathrm{in}$. This may have reflected the thick- 


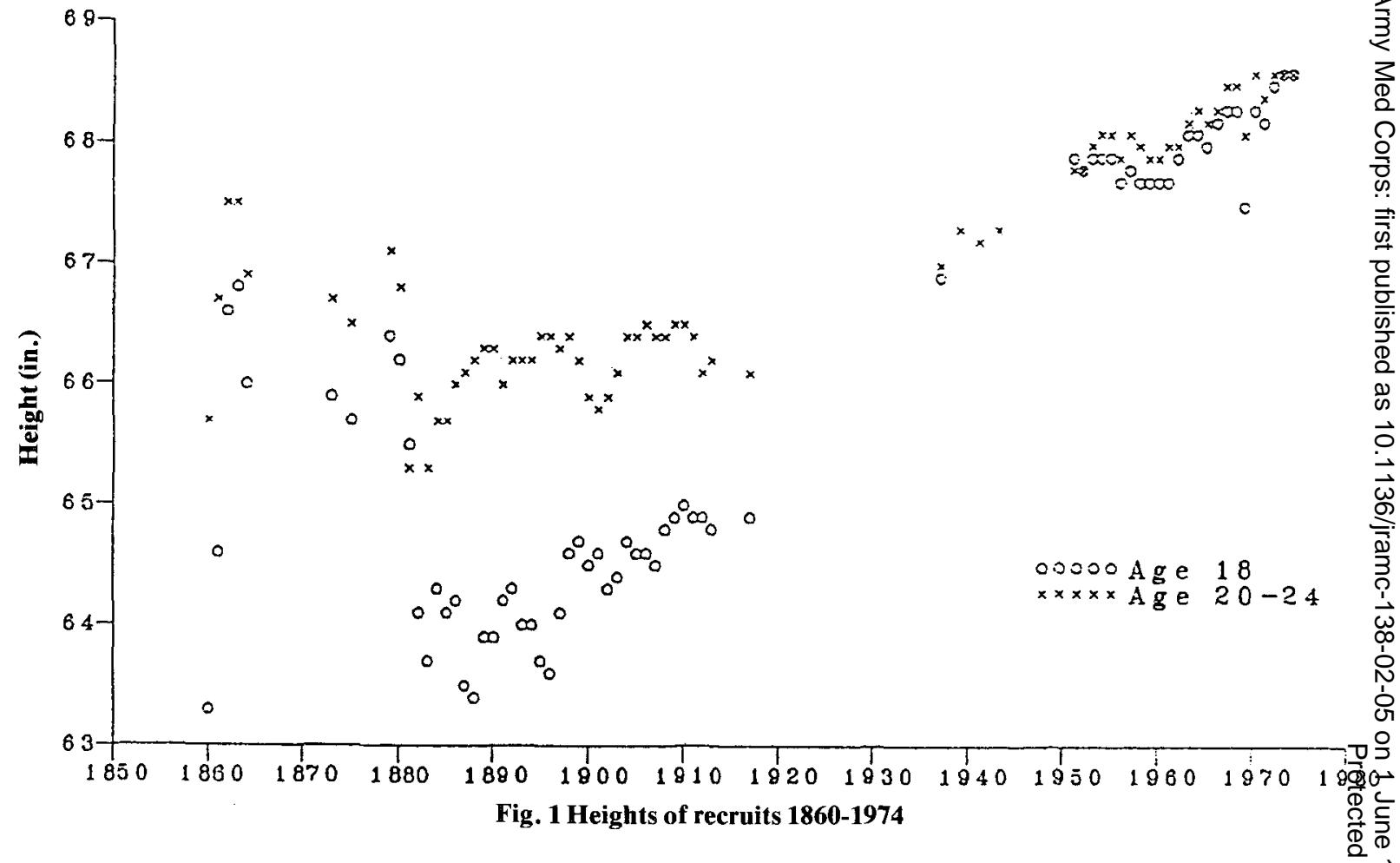

ness of the socks, or possibly the way they affected the stance. No attempt has been made in this paper to correct for such a factor since it is impossible to guess how the regulations were interpreted at any one period.

A striking feature of Fig 1 is the increase in heights over the last fifty years. Although it cannot be claimed that they exactly represent the general population, it seems reasonable to assume that the trend is a parallel one. A further feature is the closeness of the results at ages 18 and above compared with the earlier wide separation. The two end-points mentioned in the general population were the Anthropometric Committee's values for around 1875, corrected for the biases previously discussed, and the OPCS survey of 1980:
(a) 1875
age 18
65.7 in
(b) 1980 age 18
$68.8 \mathrm{in}$
21-24 66.7in
20-24 69.3in

The trend moreover, is reinforced by similar plots at age 15 and age 11 (without the benefit of military data of course) which are given in the first reference (1). Unfortunately, the data for females are much sparser but, such as they are, they confirm the trend. The children's measurements indicate that heights were increasing steadily during the period where there is a gap in the Army figures, rather than jumping suddenly to the new level. Again, at the two end-points the heights of boys were:
(a) 1875
age 11
51.7 in
(b) 1980 age 11
$56.2 \mathrm{in}$
$15 \quad 59.9$ in
$15 \quad 65.7$ in

The height of children has generally been considered an indicator of nutritional level in the population (6) its increase over a century is consistent with the view tBat nutrition has improved continuously. Children have simply become bigger but have matured earlier. It previously thought that maximum height, achieved 5 a about age 27 in 1870, and about age 19 in the late 1940 had remained unchanged at 67.5in (7). This may havg seemed a fair inference in 1948 when the observation was made, especially if the Anthropometric Committee' figures are taken at face value. Floud and his colleagues? in a book on heights in the United Kingdom (8), havẹ obtained estimates back to the mid-18th century from Army and Royal Marine records held at the Publie: Record Office in the form of Description Books whic they have sampled. They take average height to be am indicator of nutritional status in the context of a wides historical study of economic and human welfare Nowadays all the historical heights have been exceede at $69 \mathrm{in}$. Looking ahead, can an end to this process of increasing heights be foreseen? One mechanism is by further reduction of social class differentials whick appear to have narrowed over the past century; officers were found, in a 1962 survey, to be on average 1.8i⿱宀 taller than other soldiers, a difference which might i part be attributed to social class. There is some evidenced that increases in recruits' heights may come to a halt in the next few years: the continuing study by Chinn an others (9) has shown that the trend towards increased heights in 5 to 11 year old children had ceased or bea? 
considerably reduced in the period from 1979 to 1986 . This would imply a cessation of increases among recruits sometime in the present decade.

Mean heights have so far dominated the discussion, but variation about the mean must also be borne in mind and is reported in full in the first paper (1). The main result is simply stated: the standard deviation has remained at about 2.5 to 2 .6in for recruits at a given age. However the 1980 survey of the general population produced a standard deviation of 2.9in at age 20-24 (10), implying that only 2 or 3 in every 1,000 adult males lie outside the limits of $5 \mathrm{ft}$ to $6 \mathrm{ft} 6 \mathrm{in}$.

\section{Weights}

Rather less attention in the literature has been paid to weights, and they are of course more volatile and more dependent on dietary changes. The AMD Report for 1926 recorded that the average recruit gained $7 \mathrm{lb}$ in his first six months as the result, no doubt, of Army food and rigorous training. All the problems associated with height measurement have their counterpart in weight measurement with the added difficulties of weighing machine calibration and clothing. As regards the latter, although the data on recruits from 1860 onwards were stated to have been taken nude, the Anthropometric Committee's Report was not explicit on the subject of clothing, and recourse has had to be made to other publications by Roberts, the chief author, who spoke of "the whole of the indoor dress with the shoes" being included and their weight ideally recorded separately (11). He estimated that 9 or $10 \mathrm{lb}$ should be allowed for the clothing of the time. Army recruits in more recent times have been weighed with the "minimum of clothing"; in particular, boots and shoes and outer garments should have been removed and only underwear retained; consequently $1 \mathrm{~kg}$ has been deducted for the sake of comparisons. The 1980 OPCS Survey achieved an equivalent unclothed status by having each item of clothing noted on a check-list, then allowed for later. The important thing for subsequent users of the data is that there should be a statement in any publication about what clothing, if any, is included in the results. (If it has not already been made clear, all weights in this paper are unclothed).

Table 2 and Fig 2 give the average weights of recruits at age 18 last birthday and 20-24, corresponding to the heights of Table 1 and Fig 1. Comparing Fig 1 with Fig 2 over the later period, there is a greater separation between the weights of the two age-groups, because weights continue to increase when heights have ceased to do so. A pronounced dip at the time of the Boer War, both in heights and weights, is evidence of a change in the source of recruits: there were re-enlistments and embodied militia, together with fresh volunteers, but a reduced height standard, per se, should not haves affected the truncation procedure. There was indeed a weight minimum of $115 \mathrm{lb}$, and in the weight equivalen of the method used for heights the point of truncation was taken to be $110 \mathrm{lb}$. By 1904 recruits were back to pre

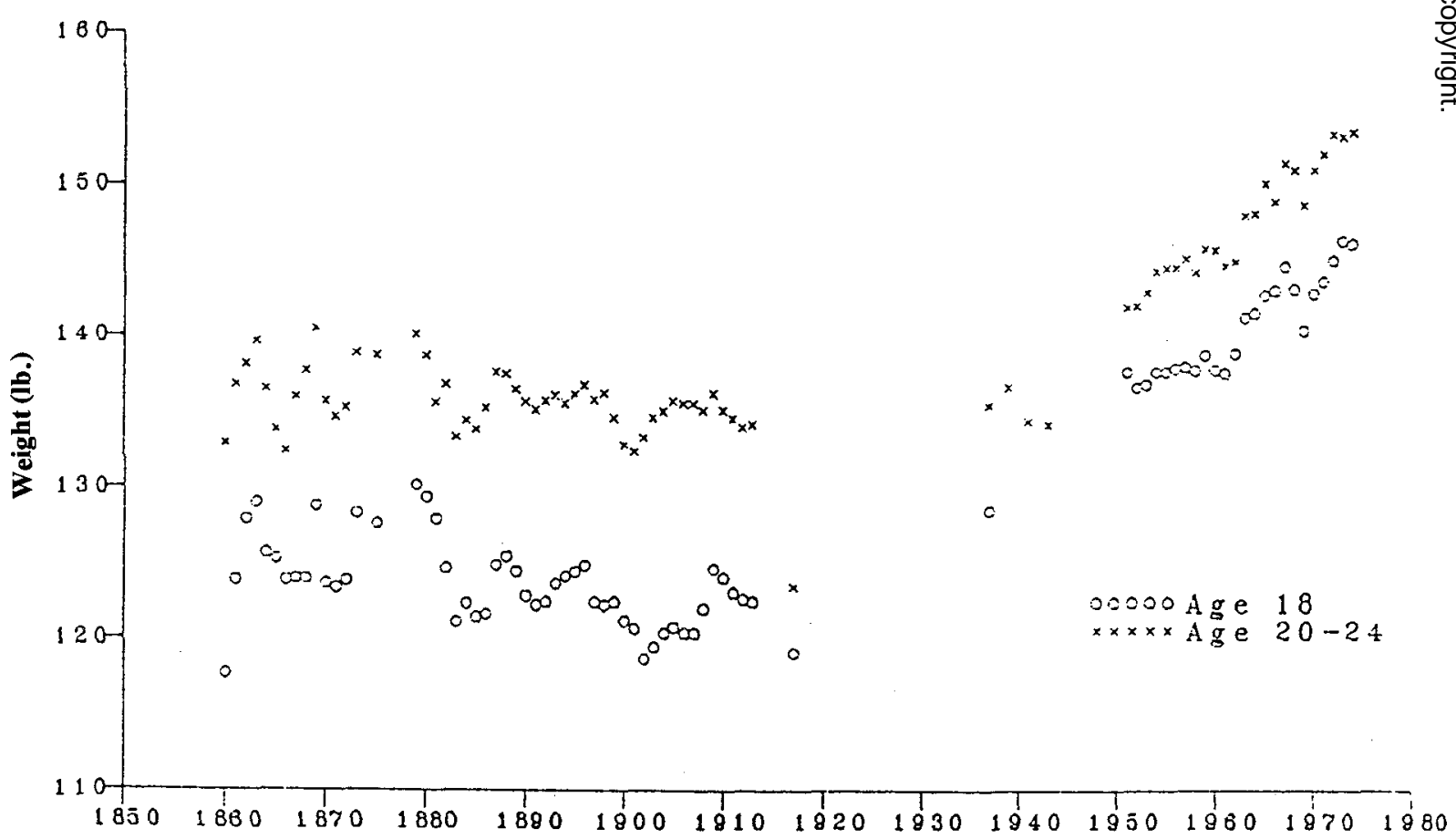

Fig. 2 Weights of recruits $1860-1974$ 
war standards, "the majority growing lads" according to the AMD Report for 1907, with "a large number out of work. In many instances suffering from want of food, and generally in poor condition".

The concern felt during the First World War about the physique of the conscripts then being called up has already been mentioned. Figs 1 and 2 indicate that while heights were about the same as for pre-war recruits, weights were substantially less, by $11 \mathrm{lb}$ in the age group 21-24. During the inter-war years the poor physical state of potential recruits induced the Army authorities to set up a Recruits' Physical Development Depot at Canterbury. Here, in 1937 and 1938, 729 of 834 "undersized recruits" underwent a three month training programme which developed them sufficiently, particularly in respect of weight and chest expansion, to

Table 2

Weights of recruits (pounds) 1860-1974

Age 18 20-24*

Age 18 20-24*

Age $18 \quad 20-24$

\begin{tabular}{lllllllll}
\hline 1860 & 117.7 & 133.0 & 1890 & 122.8 & 135.7 & & & \\
1861 & 123.8 & 136.8 & 1891 & 122.2 & 135.2 & 1941 & & 134.5 \\
1862 & 127.9 & 138.1 & 1892 & 122.4 & 135.8 & & & \\
1863 & 129.0 & 139.6 & 1893 & 123.6 & 136.1 & $1942-4$ & & 134.3 \\
1864 & 125.6 & 136.5 & 1894 & 124.1 & 135.6 & & & \\
1865 & 125.2 & 133.9 & 1895 & 124.4 & 136.2 & & & \\
1866 & 123.8 & 132.5 & 1896 & 124.8 & 136.8 & & & \\
1867 & 123.9 & 136.0 & 1897 & 122.4 & 135.9 & & & \\
1868 & 123.9 & 137.7 & 1898 & 122.2 & 136.3 & & & \\
1869 & 128.8 & 140.5 & 1899 & 122.4 & 134.7 & & & \\
1870 & 123.6 & 135.7 & 1900 & 121.2 & 132.9 & & & \\
1871 & 123.3 & 134.7 & 1901 & 120.7 & 132.5 & 1951 & 137.7 & 142.0 \\
1872 & 123.8 & 135.3 & 1902 & 118.7 & 133.4 & 1952 & 136.7 & 142.1 \\
1873 & 128.3 & 138.9 & 1903 & 119.5 & 134.7 & 1953 & 136.9 & 143.0 \\
& & & 1904 & 120.4 & 135.1 & 1954 & 137.7 & 144.4 \\
$1874-7$ & 127.6 & 138.7 & 1905 & 120.8 & 135.8 & 1955 & 137.7 & 144.6 \\
& & & 1906 & 120.4 & 135.6 & 1956 & 137.9 & 144.6 \\
& & & 1907 & 120.4 & 135.6 & 1957 & 138.0 & 145.2 \\
& & & 1908 & 122.0 & 135.2 & 1958 & 137.8 & 144.3 \\
1879 & 130.2 & 140.1 & 1909 & 124.6 & 136.3 & 1959 & 138.8 & 145.9 \\
1880 & 129.4 & 138.7 & 1910 & 124.0 & 135.2 & 1960 & 137.8 & 145.8 \\
1881 & 127.9 & 135.6 & 1911 & 123.0 & 134.7 & 1961 & 137.6 & 144.7 \\
1882 & 124.6 & 136.8 & 1912 & 122.6 & 134.1 & 1962 & 138.9 & 145.0 \\
1883 & 121.1 & 133.4 & 1913 & 122.4 & 134.3 & 1963 & 141.3 & 148.1 \\
1884 & 122.3 & 134.5 & & & & 1964 & 141.6 & 148.2 \\
1885 & 121.4 & 133.9 & & & & 1965 & 142.8 & 150.2 \\
1886 & 121.6 & 135.3 & & & & 1966 & 143.1 & 149.0 \\
1887 & 124.8 & 137.6 & $1917-8$ & 119.1 & 123.4 & 1967 & 144.7 & 151.5 \\
1888 & 125.4 & 137.5 & & & & 1968 & 143.2 & 151.1 \\
1889 & 124.4 & 136.5 & & & & 1969 & 140.5 & 148.8 \\
& & & & & & 1970 & 142.9 & 151.1 \\
& & & & & & 1971 & 143.7 & 152.1 \\
& & & 1937 & 128.5 & 135.5 & 1972 & 145.1 & 153.4 \\
& & & & & & 1973 & 146.4 & 153.2 \\
& & & 1939 & & 136.7 & 1974 & 146.2 & 153.5 \\
& & & $* 21-24$ before & 1919 & & & \\
\hline & & & & & & & &
\end{tabular}

meet the entry standards of their regimental depots (12) In the context of minimum standards for recruit entry is interesting to note the emphasis placed on ches expansion. Inadequate chest measurements were the second highest cause, after underweight, of the rejection of recruits in 1908; it was the contemporary doctrine the tall thin men, specifically Guardsmen, were particular susceptible to phthisis, or tuberculosis. In the Secon World War the Ministry of Food set up a study provide early warning of any decline in body weig which might indicate serious food shortages in the civf population (13). The conclusion was that in 1943 weigh were about 3lb below their peace-time level but hat recovered by 1950 . Of course, in 1917-18 food supplies were much more severely curtailed. The smaller decrease in body weight in the Second World War had nog demonstrable ill effect on health (14) although puble dissatisfaction with the food supply was reported.

As with heights, we compare the Anthropometr Committee's values for weights with those of the 198' survey:

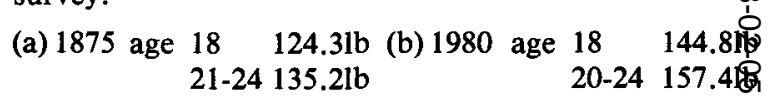

Again they fit the trend in recruits' weights quite wel\$. The similar trends in boys' weights are demonstrated at the same end-points:
(a) 1875 age 11
$57.51 \mathrm{~b}$
83.6lb
(b) 1980 age 11
15
78 赵席
$120 \% \mathrm{lb}$

It is indeed striking that the average weight at age 14 1980 is only $4 \frac{1}{2}$ lb short of that at age 15 a hundred years earlier; and at age 15 in 1980 is similarly close to tro average weight at age $18 \mathrm{a}$ hundred years before.

\section{Quetelet's Index and Obesity}

One of the principal applications, and indeed one of the rewards from the continuous collection of the heigh and weights data from Army recruits is the assessme over the years of body build. To this end the most usef indicator is the Quetelet index (Q) named after the celebrated Belgian social statistician Adolphe Quetetet (1796-1874); it is also known as the body mass inde (BMI) or obesity index (OI). Defined as $w / h^{2}$, or metric units $\mathrm{kg} / \mathrm{m}^{2}$, it is valid for both sexes and appeats to give almost as good a measure of body fat as 10 laboratory methods of body composition estimation $\overline{\text { or }}$ skinfold measurements. While the index is primarily $\bar{g}$ f value in assessing the physical status of a population ofa sub-section of the population such as the Services it $9 s$ also applicable to individuals, and arbitrary standards have been proposed for adults which suggest an index value of 20 or less as underweight, 25 or more overweight, and in excess of 30 as obese. Army standards were set somewhat more stringently in 1978. In a bookfert for medical officers (15) the desirable limits were fixed between 21.0 and 24.7. Not all soldiers met these quirements, and medical sanctions in the form धff downgrading were instituted for those who were obese 
Table 3

Army Recruits; Quetelet Index 1860 and 1974

\begin{tabular}{ccc} 
Age (years) & 18 & $20-24$ \\
\hline 1860 & 20.7 & 21.7 \\
1974 & 21.9 & 23.0 \\
\hline
\end{tabular}

and unfit. Historically, Table 3 shows the average change that has occurred during the 120 years of data collection, implying greater numbers above the limit. These data, along with the information from studies on serving soldiers, point to the problem - for the nation as well as for the Army - of obesity as an increasingly serious public health malady. It is not the purpose of this paper to discuss the ill effects of obesity; the association with an increased morbidity and mortality is well documented. For the Services, who have a requirement for a very high standard of physical fitness, obesity is even more undesirable.

The physical state of Army recruits necessarily reflects the condition of the population from which they are drawn and it is salutary to ponder the changes in status that have occurred since 1860 , taking note of the reported trends in body weight and height (see Figs 1 and 2) which act as a key to the social and medical well being of young adults. For the Army, incipient obesity has been the spur to an enhanced awareness of the need to examine the effects of recruits' physical training and also to monitor the record of trained soldiers' weight changes throughout their service. Finally, useful as is the Quetelet index for both groups and individuals it remains a relatively coarse investigative tool and cannot discern the body component changes which may stem from an intensive Army regime of physical development. A study of 254 recruits, average age 191/2, at the Army's centralized Recruit Selection Centre in 1972 (16) demonstrated, over a twelve-week training period, an increase in mean body weight of $0.3 \mathrm{~kg}$ and a rise in the mean level of $Q$ from 22.2 to 22.5 ; this small increase was accompanied by a significant decrease in body fat measured from skinfold thickness - of $8.6 \%$, indicating a gain of muscle at the expense of fat. Nonetheless, heights and weights, along with $Q$ as the derived index, remain the best method yet of maintaining a true record of physical stature. The reader's notice is drawn again to the sad fact that the publication of recruit height and weight data ceased in 1975. A plea is made for publication to be restarted as a matter of both Army and national interest.

\section{REFERENCES}

1. ROSENBAUM S. 100 years of heights and weights. $J R$ Statist Soc $A$ 1988; 151: 276-309.

2. KNIGHT I. The heights and weights of adults in Great Britain. Office of Population Censuses and Surveys. London: HMSO, 1984.

3. MARTIN W J. The physique of young adult males. Medical Research Council Memorandum No 20. London: HMSO, 1949.

3. Clements E M B, Pickett K G. Stature and weight of men from England and Wales in 1941. Br J Prev Soc Med 1957; 11: 51-60.

5. Morant G M. Heights and weights of German civilians in 1946-7 and R.A.F. and other British series. Biometrika 1948 ; 35: 368-396.

6. ACHESON D. Nutritional monitoring of the health of the nation. JR Soc Hlth 1987; 6: 209-214.

7. Morant G M. Changes in the size of British people in the past hundred years. In Homenaje a Don Luis De Hoyos Sainz 1949; 1: 235-241, Madrid.

8. Floud R C, WachTER K W, Gregory A. Height, Health and History. Cambridge: Cambridge University Press, 1990.

9. Chinn S, Rona R J, Price C E. The secular trend in height of primary school children in England and Scotland. Ann Hum Biol 1989; 16: 387-395.

10. Rosenbaum S, Skinner R K, Knight I B, Garrow $S$. A survey of heights and weights of adults in Great Britain, 1980. Ann Hum Biol 1985; 12: 115-127.

11. RoberTs C. A manual of anthropometry. London Churchill, 1878.

12. CRAwFord J A. The work at the Recruits' Physica Development Depot, Canterbury. J R Army Med Corps 1939; 73: 1-39.

13. KemsLeY, W F F. Letter to the Editors. $J R$ Statist Soc $A$ 1989; 152: 249-250.

14. Harries J M, Hollingsworth D F. Food supply, body weight, and activity in Great Britain, 1943-9. BrMed J1953; i: 75-78.

15. Crowdy J P. Obesity and the Soldier. Army Medical Directorate Bulletin (Third Series). London: Ministry of Defence, 1978.

16. Vogel J A, Crowdy J P, AMor A F, Worsley D E. Changes in Aerobic Fitness and Body Fat during Army Recruit Training. Eur J Appl Physiol 1978; 40: $37-43$. 